\title{
Optimisation of Concentrator in the Solar Photonic Optoelectronic Transformer: Comparison of Geometrical Performance and Cost of Implementation
}

\author{
F. Muhammad-Sukki ${ }^{1}$, R. Ramirez-Iniguez ${ }^{1}$, S. G. McMeekin ${ }^{1}$, B. G. Stewart ${ }^{1}$ and B. Clive $^{2}$ \\ ${ }^{1}$ School of Engineering and Computing \\ Glasgow Caledonian University \\ Cowcaddens Road, G40BA, Glasgow, Scotland (UK) \\ Phone/Fax number: +44(0)141331 8939/+44(0)141331 3690, e-mail: firdaus.muhammadsukki@gcu.ac.uk, \\ roberto.ramireziniguez@gcu.ac.uk, scott.mcmeekin@gcu.ac.uk, $\underline{\text { b.stewart@gcu.ac.uk }}$ \\ ${ }^{2}$ Solar Empower Ltd \\ 74-75 Brunner Road, London, E17 7NW, England, (UK) \\ Phone/fax: +44 208520 8267, e-mail: core@btinternet.com
}

\begin{abstract}
The Solar Photonic Optoelectronic Transformer (SPOT) is one of the components of the SolarBrane, a Building Integrated Photovoltaic (BIPV) system developed by SolarEmpower Ltd. The SPOT employs 2-D linear dielectric totally internally reflecting concentrator (DTIRC) to increase the collection efficiency of the sun's rays and reduce the amount of photovoltaic (PV) material used. In this paper, an optimised DTIRC design for the SPOT, based on the maximum concentration method (MCM), is discussed. Next, the geometrical properties of the optimised DTIRC design are explained and compared to a DTIRC based on the phase conserving method (PCM). A cost analysis of implementing the MCM is also presented. The results obtained from simulations in MATLAB show that the MCM offers higher geometrical concentration gains and at the cost of increasing the concentrator size. The new optimised concentrator offers a lower cost of implementation, shorter payback period and an even higher annual return as compared to the existing design.
\end{abstract}

\section{Key words}

Solar concentrator, dielectric totally internally reflecting concentrator, maximum concentration method, phase conserving method, geometrical concentration gain.

\section{Introduction}

SolarEmpower Ltd. aims to exploit solar power as well as producing a cheap, cost competitive Building Integrated Photovoltaic (BIPV) system into the PV market. SolarBrane [1] is a BIPV system developed by SolarEmpower Ltd after years of research. It is a static solar device. Unlike conventional solar photovoltaic (PV) systems which only generate electricity, SolarBrane utilises both direct and indirect solar radiations to produce electricity, hot water, space heating, illumination and ventilation for a building which reduces the power consumption of a building [1],[2]. Figure 1 shows the diagram of a SolarBrane.
To reduce the production cost of the system, a solar concentrator is used in the design. A solar concentrator is one of the devices used in the BIPV system that maximizes the collection of solar light and focuses the light to a smaller exit area, at which a PV cell is attached. While traditional solar PVs use a large area of silicon cell, the introduction of a concentrator in the design enables SolarBrane to use approximately $30 \%$ of the total silicon whilst maintaining the same output power [1],[2].

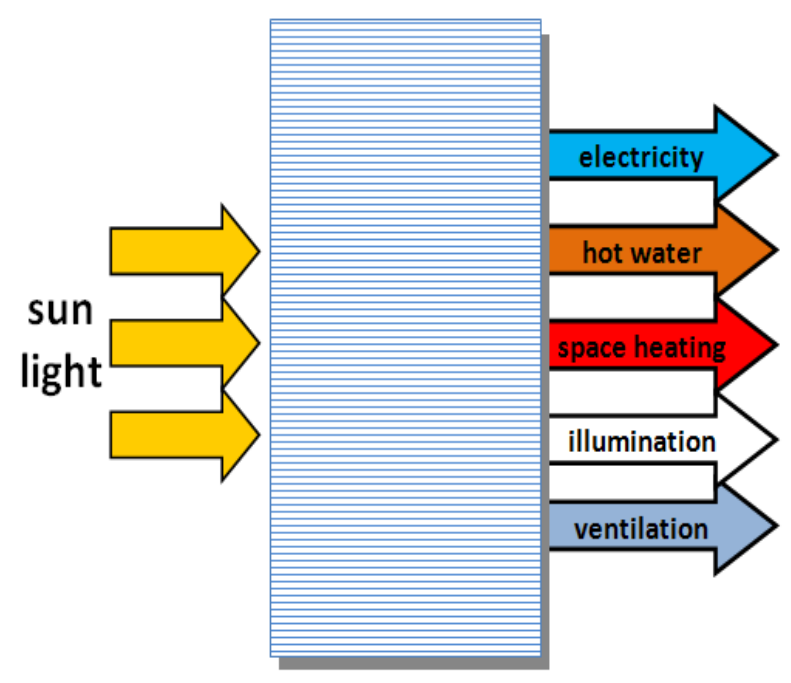

Figure 1: The SolarBrane [1]

An important component of the SolarBrane is the Solar Photonic Optoelectronic Transformer (SPOT). Currently, the optical concentrator incorporated in the SPOT is a 2-D extrusion of a dielectric totally internally reflecting concentrator (DTIRC) profile (see Figure 2) and is deposited on a rectangular PV cell cooled by water or air depending on the application. This concentrator has proven to provide three advantages as compared to alternative optical elements such as a conical 
concentrator or a compound parabolic concentrator (CPC) [3], and these are listed below.

1. It provides higher optical gain which is useful to increase the cell performance efficiency. It also means that a smaller area of PV cell can be incorporated in the design.

2. It is a more compact structure. A concentrator of a more compact size means less material is needed, which results in a lower manufacturing cost of the whole solar cell system.

3. It has potentially a large field-of-view (FOV). This can be selected during the design stage and can be used to eliminate the need for expensive mechanical tracking which consumes a lot of power.

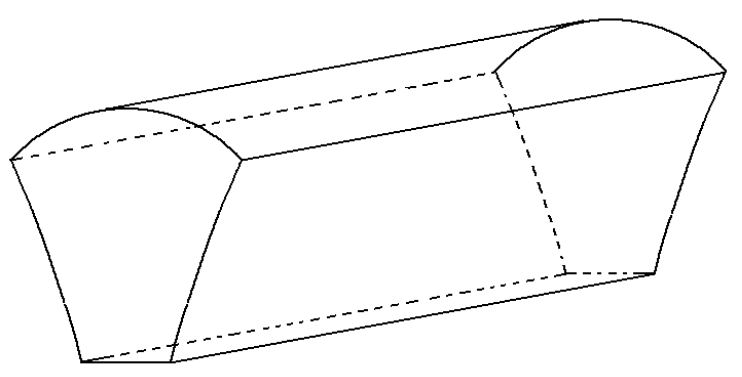

Figure 2: Solar concentrator in the SPOT

The current DTIRC design is based on the phase conserving method (PCM) developed by Ning et. al [3] in 1987. However, further optimization to improve the performance on the existing concentrator is desirable.

\section{General DTIRC Design}

A DTIRC consists of three parts; a curved front surface, a totally internally reflecting side profile and an exit aperture (see Figure 3). When the rays hit the front curved surface, they are refracted and directed to the side profile. Upon hitting the sidewall, they are totally internally reflected to the exit aperture. Outside the range of the acceptance angle, the rays exit from the side profile, missing the PV cell [4].

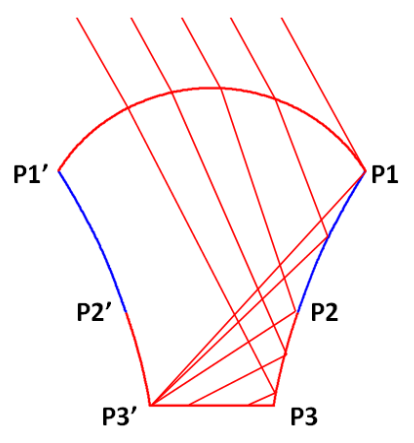

Figure 3: General design of a DTIRC

The side profile of a DTIRC consists of two curved profiles as illustrated in Figure 3. The upper profile covers from $\mathrm{P} 1$ to $\mathrm{P} 2$ and the lower part from $\mathrm{P} 2$ to $\mathrm{P} 3$. Any extreme rays hitting portion $\mathrm{P} 1$ to $\mathrm{P} 2$ will be directed to the point P3' after a single total internal reflection (TIR). The ray hitting $\mathrm{P} 2$ exits at $\mathrm{P} 3$ ' although it barely satisfies the TIR condition. For portion P2 to P3, there are two ways to create this profile.

\section{- Based on the MCM:}

Impose a condition such that all the rays experience a single TIR and arrive at the exit aperture, without restricting the exit angle and the incident angle, which results in achieving the maximum possible concentration.

\section{- Based on the PCM:}

Create a profile that allows the rays to exit in parallel, which enables the rays to exit with a welldefined wavefront.

Although both methods can be used to create similar structures, the first technique offers slightly higher concentration at the cost of increasing the size of the concentrator. The DTIRC is proven to have the capability to achieve concentrations close to the theoretical maximum limit [3].

\section{Maximum Concentration Method}

To simulate a DTIRC based on the MCM in a Cartesian coordinate system, the 2-D solution is obtained first to produce the $\mathrm{x}$ and $\mathrm{y}$-coordinates of the profile. The 3-D version is obtained by extending the $2-\mathrm{D}$ coordinates over the z-plane.

The 2-D representation requires six input parameters, namely the front surface arc angle $(\varphi)$, the acceptance angle $\left(\theta_{a}\right)$, the dimension of exit aperture $\left(d_{0}\right)$, the trial length of the entrance aperture $\left(d_{1}\right)$, the index of refraction of the dielectric $(n)$ and the number of extreme rays $(N)$.

SPOT System Concentrator - MCM

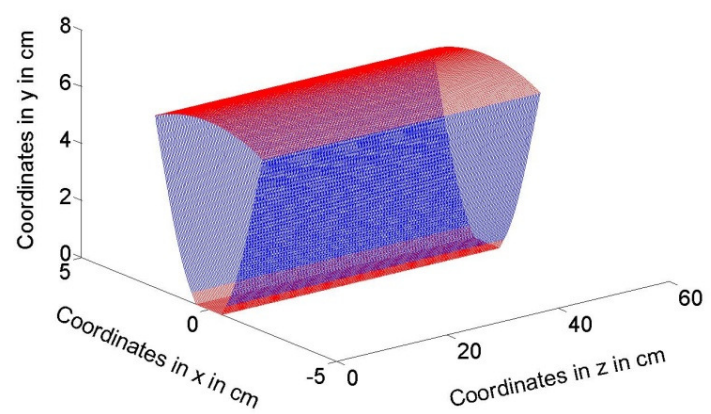

Figure 4: 3-D design for a DTIRC based on the MCM.

Based on the input variables, a computer program is used to calculate the trial height, which is later used to calculate the coordinates of the side wall. This calculation takes into account the number of extreme rays entering the concentrator at the critical angle. Once it is completed, the program compares the trial entrance aperture with the calculated aperture. A new entrance aperture is computed from the difference between the two 
apertures. A number of iterations take place until the difference between both apertures is within a predetermine error value [3]. Figure 4 shows the simulated diagram of the new concentrator design based on the MCM.

To simplify the analysis, the following values are fixed throughout this paper: $d_{0}=1 \mathrm{~cm}$ and $N=200$.

\section{Performance Analysis}

The analysis of the main geometrical characteristics of a DTIRC based on MCM compared to one produced using the PCM is done varying three parameters, by varying the acceptance angle $\left(\theta_{a}\right)$, the front surface arc angle $(\varphi)$ and the index of refraction of the dielectric material $(n)$. As mentioned earlier, the other two parameters are fixed to ease the analysis. The number of extreme rays $(N)$ is used to provide the number of $x-y$ coordinates as well as the numerical precision. The effect that the input parameters have on the geometrical concentration, the entrance diameter and the total height of the concentrator are then evaluated. Table I shows the effect of different acceptance angles, Table II indicates the effect of varying the front surface arc angle and Table III presents the effects of changing the index of refraction of the dielectric material. In each table, the comparison of the dimension of the concentrator as well as the geometrical concentration gain between using the PCM and MCM are shown in detail. The improvement of the optimised design is also calculated as a percentage value in relation to the current design and is included in each table.
The geometrical concentration gain for a 2-D concentrator is defined as the ratio of the entrance aperture diameter to the exit aperture diameter [4]. In general, the DTIRC gain is inversely proportional to the acceptance angle and to the arc angle. As the front surface becomes more curved, rays are bent more sharply. It is harder to satisfy the total internal reflection condition, thus the gain is reduced [3]. It is also concludes that a DTIRC will achieve larger gain if it is produced by using a higher index of refraction material.

Table I shows an increment of between $0.94 \%$ and $2.33 \%$ in terms of gain, and increments of between $0.94 \%$ and $2.33 \%$ and between $0.79 \%$ and $1.81 \%$ in terms of the entrance diameter and total height respectively. In Table II, the gain increases to between $0.05 \%$ and $2.77 \%$ while entrance diameter and the total height increase between $0.05 \%$ and $2.77 \%$ and $0.04 \%$ and $2.31 \%$ respectively. In Table III, the percentage increase in terms of the gain and the size of the concentrator reduce with increasing refractive index. The percentage increase of the gain, entrance diameter and total height reduce from $1.21 \%$ to $0.57 \%$, from $1.21 \%$ to $0.57 \%$ and from $0.98 \%$ to $0.47 \%$ respectively.

Observing the three tables, in all cases the MCM offers a higher gain than the PCM. Both the total height and the entrance diameter of the new concentrator design are slightly greater than the current concentrator design. This implies that the MCM produces a slightly larger concentrator structure.

Table I: Comparison of Geometrical Concentration Gain vs Acceptance Angle (Index $=1.5$, Arc Angle $=35^{\circ}$, Exit Aperture $=1 \mathrm{~cm}$ )

\begin{tabular}{|c|c|c|c|c|c|c|c|c|c|}
\hline \multirow{2}{*}{$\begin{array}{l}\text { Accept- } \\
\text { ance } \\
\text { Angle } \\
\left(^{\circ}\right)\end{array}$} & \multicolumn{3}{|c|}{$\begin{array}{c}\text { Phase } \\
\text { Conserving } \\
\text { Method } \\
\end{array}$} & \multicolumn{3}{|c|}{$\begin{array}{c}\text { Maximum } \\
\text { Concentration } \\
\text { Method } \\
\end{array}$} & \multicolumn{3}{|c|}{$\begin{array}{l}\text { Percentage of Change } \\
(\%)\end{array}$} \\
\hline & $\begin{array}{l}\text { Entrance } \\
\text { diameter } \\
(\mathrm{cm})\end{array}$ & $\begin{array}{l}\text { Total } \\
\text { height } \\
(\mathrm{cm})\end{array}$ & $\begin{array}{l}\text { Gain } \\
d_{l} / d_{0}\end{array}$ & $\begin{array}{l}\text { Entrance } \\
\text { diameter } \\
(\mathrm{cm})\end{array}$ & $\begin{array}{l}\text { Total } \\
\text { height } \\
(\mathrm{cm})\end{array}$ & $\begin{array}{l}\text { Gain } \\
d_{l} / d_{0}\end{array}$ & $\begin{array}{l}\text { Entrance } \\
\text { diameter }\end{array}$ & $\begin{array}{l}\text { Total } \\
\text { height }\end{array}$ & Gain \\
\hline 18.00 & 4.63 & 7.13 & 4.63 & 4.68 & 7.18 & 4.68 & 0.94 & 0.79 & 0.94 \\
\hline 20.00 & 4.15 & 6.17 & 4.15 & 4.20 & 6.22 & 4.20 & 1.09 & 0.90 & 1.09 \\
\hline 22.00 & 3.76 & 5.40 & 3.76 & 3.81 & 5.45 & 3.81 & 1.32 & 1.07 & 1.32 \\
\hline 24.00 & 3.44 & 4.77 & 3.44 & 3.49 & 4.83 & 3.49 & 1.64 & 1.31 & 1.64 \\
\hline 26.00 & 3.16 & 4.25 & 3.16 & 3.22 & 4.31 & 3.22 & 1.89 & 1.49 & 1.89 \\
\hline 28.00 & 2.92 & 3.81 & 2.92 & 2.99 & 3.88 & 2.99 & 2.33 & 1.81 & 2.33 \\
\hline
\end{tabular}

Table II: Comparison of Geometrical Concentration Gain vs Arc Angle $\left(\right.$ Index $=1.5$, Acceptance Angle $=20^{\circ}$, Exit Aperture $\left.=1 \mathrm{~cm}\right)$

\begin{tabular}{|c|c|c|c|c|c|c|c|c|c|}
\hline \multirow{2}{*}{$\begin{array}{c}\text { Arc } \\
\text { Angle } \\
\left({ }^{\circ}\right)\end{array}$} & \multicolumn{3}{|c|}{$\begin{array}{c}\text { Phase } \\
\text { Conserving } \\
\text { Method }\end{array}$} & \multicolumn{3}{|c|}{$\begin{array}{c}\text { Maximum } \\
\text { Concentration } \\
\text { Method }\end{array}$} & \multicolumn{3}{|c|}{$\begin{array}{c}\text { Percentage of Change } \\
(\%)\end{array}$} \\
\hline & $\begin{array}{l}\text { Entrance } \\
\text { diameter } \\
(\mathrm{cm})\end{array}$ & $\begin{array}{c}\text { Total } \\
\text { height } \\
(\mathrm{cm})\end{array}$ & $\begin{array}{l}\text { Gain } \\
d_{l} / d_{0}\end{array}$ & $\begin{array}{l}\text { Entrance } \\
\text { diameter } \\
(\mathrm{cm})\end{array}$ & $\begin{array}{c}\text { Total } \\
\text { height } \\
(\mathrm{cm})\end{array}$ & $\begin{array}{l}\text { Gain } \\
d_{1} / d_{0}\end{array}$ & $\begin{array}{l}\text { Entrance } \\
\text { diameter }\end{array}$ & $\begin{array}{c}\text { Total } \\
\text { height }\end{array}$ & Gain \\
\hline 10.00 & 4.32 & 9.08 & 4.32 & 4.32 & 9.08 & 4.32 & 0.05 & 0.04 & 0.05 \\
\hline 20.00 & 4.26 & 7.60 & 4.26 & 4.27 & 7.62 & 4.27 & 0.22 & 0.18 & 0.22 \\
\hline 30.00 & 4.19 & 6.58 & 4.19 & 4.22 & 6.61 & 4.22 & 0.66 & 0.54 & 0.66 \\
\hline 35.00 & 4.15 & 6.17 & 4.15 & 4.20 & 6.21 & 4.20 & 1.09 & 0.90 & 1.09 \\
\hline 40.00 & 4.11 & 5.80 & 4.11 & 4.18 & 5.88 & 4.18 & 1.76 & 1.46 & 1.76 \\
\hline 45.00 & 4.06 & 5.47 & 4.06 & 4.17 & 5.59 & 4.17 & 2.77 & 2.31 & 2.77 \\
\hline
\end{tabular}


Table III: Comparison of Geometrical Concentration Gain vs Index of Refraction (Arc Angle $=30^{\circ}$, Acceptance Angle $=20^{\circ}$, Exit Aperture $=1 \mathrm{~cm}$ )

\begin{tabular}{|c|c|c|c|c|c|c|c|c|c|}
\hline \multirow{2}{*}{$\begin{array}{l}\text { Refractive } \\
\text { Index }\end{array}$} & \multicolumn{3}{|c|}{$\begin{array}{l}\text { Phase } \\
\text { Conserving } \\
\text { Method }\end{array}$} & \multicolumn{3}{|c|}{$\begin{array}{c}\text { Maximum } \\
\text { Concentration } \\
\text { Method } \\
\end{array}$} & \multicolumn{3}{|c|}{$\begin{array}{l}\text { Percentage of Change } \\
(\%)\end{array}$} \\
\hline & $\begin{array}{l}\text { Entrance } \\
\text { diameter } \\
(\mathrm{cm})\end{array}$ & $\begin{array}{c}\text { Total } \\
\text { height } \\
(\mathrm{cm})\end{array}$ & $\begin{array}{l}\text { Gain } \\
d_{l} / d_{0}\end{array}$ & $\begin{array}{l}\text { Entrance } \\
\text { diameter } \\
(\mathrm{cm})\end{array}$ & $\begin{array}{l}\text { Total } \\
\text { height } \\
(\mathrm{cm})\end{array}$ & $\begin{array}{l}\text { Gain } \\
d_{l} / d_{0}\end{array}$ & $\begin{array}{l}\text { Entrance } \\
\text { diameter }\end{array}$ & $\begin{array}{c}\text { Total } \\
\text { height }\end{array}$ & Gain \\
\hline 1.40 & 3.74 & 6.12 & 3.74 & 3.78 & 6.18 & 3.78 & 1.21 & 0.98 & 1.21 \\
\hline 1.43 & 3.88 & 6.26 & 3.88 & 3.92 & 6.32 & 3.92 & 1.06 & 0.86 & 1.06 \\
\hline 1.45 & 3.98 & 6.36 & 3.98 & 4.01 & 6.41 & 4.01 & 0.96 & 0.78 & 0.96 \\
\hline 1.47 & 4.07 & 6.45 & 4.07 & 4.10 & 6.49 & 4.10 & 0.80 & 0.66 & 0.80 \\
\hline 1.50 & 4.19 & 6.58 & 4.19 & 4.22 & 6.61 & 4.22 & 0.66 & 0.54 & 0.66 \\
\hline 1.52 & 4.28 & 6.66 & 4.28 & 4.30 & 6.69 & 4.30 & 0.57 & 0.47 & 0.57 \\
\hline
\end{tabular}

\section{Cost of Implementation Analysis}

The Feed-in Tariff (FIT) is one of the incentives offered by the UK government to increase the renewable energy penetration especially for small scale electricity generation [5]. For any solar panel installed in existing building, the FIT could potentially benefit the participants for a contract period of 25 years in three ways: (1) All the electricity generated will be paid $41.3 p$ per kWh; (2) Any electricity exported into the grid will be paid 3.0p per $\mathrm{kWh}$, and (3) The electricity generated can be used by the participants, which reduces the amount of electricity required. Figure 5 shows the conceptual diagram of an FIT implementation in a UK house. On average, the current cost of electricity is $12.5 \mathrm{p}$ per kWh [5]-[6].

To date, a typical UK household consumes about $22,000 \mathrm{kWh}$ per year [7], where $58 \%$ of the energy is used for space heating, $23 \%$ for hot water, $16 \%$ for lighting and appliances and 3\% for cooking [8]. SolarBrane could be the chosen BIPV system as compared to traditional solar PVs for the installation in residential and office buildings because of its main advantages; cheaper initial cost due to less PV used and much better performance [1]-[2].

This section analyses the cost of implementing a $2.5 \mathrm{kWp}$ PV system on a UK house using three types of PV panel; traditional PV system, current SolarBrane and optimised SolarBrane. Then, based on the FIT scheme, the performance of the PV is analysed and the cost savings from the scheme is calculated. Finally, the payback period and the return on investment of each PV panel type are presented and compared. Table IV summarises the whole calculation in this section for all three cases.

Looking at Table I and II, it is observed that the larger the acceptance angle and the front surface arc angle of the concentrator, the larger the difference in gain percentage and the size percentage. A larger concentrator means that the optimised system will require more material to produce the concentrator. However, higher gain can also mean that a smaller PV cell could be used in the SolarBrane.
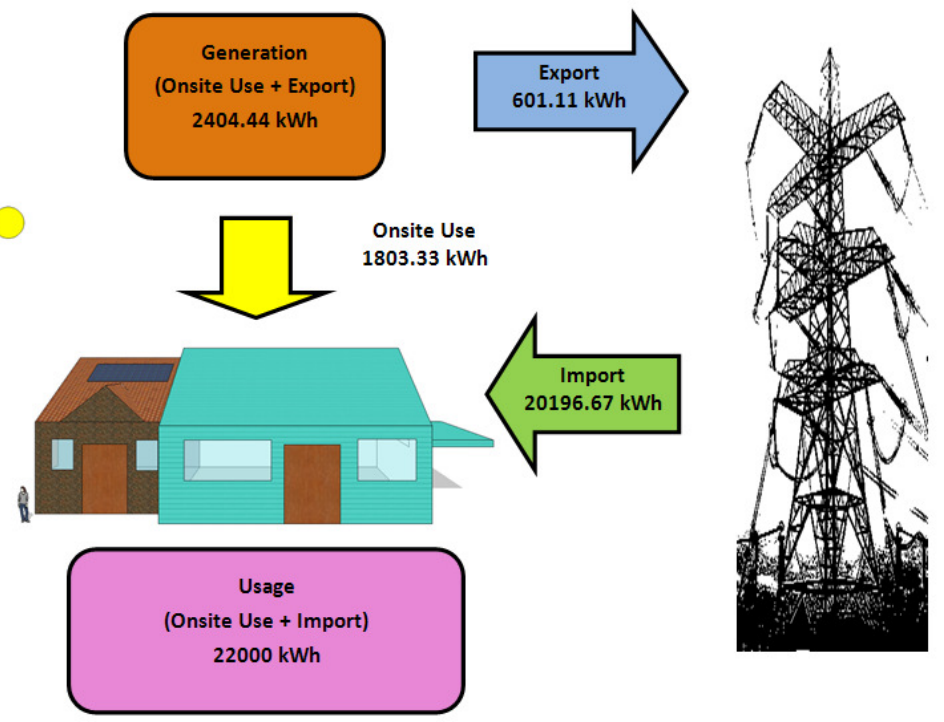

Figure 5: The FIT implementation 
Table IV: The analysis of using the traditional solar PV, current SolarBrane and optimised SolarBrane

\begin{tabular}{|c|c|c|c|c|}
\hline Item & & $\begin{array}{c}\text { Traditional } \\
\text { Solar PV }\end{array}$ & $\begin{array}{c}\text { Current } \\
\text { SolarBrane }\end{array}$ & $\begin{array}{l}\text { Optimised } \\
\text { SolarBrane }\end{array}$ \\
\hline \multicolumn{5}{|c|}{ 1. Installation Cost Breakdown } \\
\hline & PV Material $(£)$ & $7,500.00$ & $2,250.00$ & $2,187.68$ \\
\hline $\mathrm{b}$ & Concentrator $(£)$ & 0.00 & 221.34 & 235.51 \\
\hline & Other Cost $\quad(£)$ & $5,000.00$ & $5,000.00$ & $5,000.00$ \\
\hline & Total Cost & $12,500.00$ & $7,471.34$ & $7,423.19$ \\
\hline \multicolumn{5}{|c|}{ Income from the FIT Scheme } \\
\hline $\mathrm{a}$ & Generation of Electricity $\quad-2404.44 \mathrm{kWh} \times 41.3 \mathrm{p} / \mathrm{kWh}(\mathfrak{f})$ & \multicolumn{3}{|c|}{993.03} \\
\hline & Exporting the Electricity $-601.11 \mathrm{kWh} x \quad 3.0 \mathrm{p} / \mathrm{kWh}(\mathfrak{f})$ & \multicolumn{3}{|c|}{18.03} \\
\hline \multicolumn{2}{|r|}{ 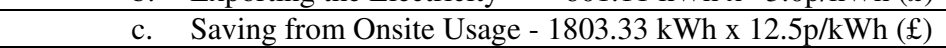 } & \multicolumn{3}{|c|}{225.42} \\
\hline \multirow{2}{*}{\multicolumn{2}{|c|}{$\begin{array}{l}\text { Total Annual Revenue } \\
\text { Total Revenue after } 25 \text { years }(£)\end{array}$}} & \multicolumn{3}{|c|}{$1,236.48$} \\
\hline & & \multicolumn{3}{|c|}{$30,912.05$} \\
\hline \multicolumn{5}{|c|}{ 3. Investment Analysis } \\
\hline & Payback Period & 10.11 & 6.04 & 6.00 \\
\hline & Average Return on Investment (\%) & 5.89 & 12.55 & 12.66 \\
\hline
\end{tabular}

Consider one of the examples of a BIPV installation done by Planet Solar Ltd. where a $2.5 \mathrm{kWp}$ system was installed, covering a roof's area of $17.00 \mathrm{~m}^{2}$, and at a cost of $£ 12,500.00^{1}$ [9]. According to [10], the cost of a PV material contributes to about $60 \%$ of the total cost; hence it is possible to suggest that the cost of PV material will be $£ 7,500.00$. This system is a traditional solar PV installation which does not implement any concentrator in it.

The current SolarBrane however only uses $30 \%$ of the $\mathrm{PV}$ material [1]; therefore the cost of PV is around $£ 2,250.00$. Based on the calculation in [11], the cost of implementing the concentrator in the system is estimated to be around $£ 13.02^{2}$ per square metre, and therefore is equals to $£ 221.34$ for an installation that covers an area of $17.00 \mathrm{~m}^{2}$. Supposing the rest of the costs remain the same, the total cost of implementing the current design is estimated to be $£ 7,471.34$.

Now, consider the optimised SolarBrane that uses the DTIRCs based on MCM. From the information in Table II, if the front surface arc angle is set to be $45^{\circ}$, the increment of the entrance diameter, the total height and the geometrical gain are $2.77 \%, 2.31 \%$ and $2.77 \%$ respectively. If SolarEmpower Ltd. opted to use the optimised concentrator whilst maintaining the same electrical output as the existing concentrator, the amount of PV material used can be reduced by $2.77 \%$ which translates to a cost of $£ 2,187.64$. The concentrator's volume will be increased by approximately $6.40 \%$, which is roughly around $£ 235.50$. The total cost of implementing the new concentrator is $£ 7,423.14$. The new concentrator could therefore save about £48.21, which contributes to a reduction of total cost by approximately $0.65 \%$. It can also be seen that by

${ }^{1}$ UK's Energy Saving's Trust estimates that cost to install an average solar PV system of $2.2 \mathrm{kWp}$ is around $£ 12,000.00$ [6].

${ }^{2}$ The system in [11] employs the extrusion of CPCs in an area of $0.60 \mathrm{~m}^{2}$, which costs about $£ 17.50$. To produce a concentrator in an area of $1.00 \mathrm{~m}^{2}$, the cost is estimated to be roughly $£ 29.17$. Since the size of the DTIRC is less than $45 \%$ of the CPC, the cost of implementing the DTIRC in a $1.00 \mathrm{~m}^{2}$ is estimated to be $£ 13.02$ per square metre. implementing the current SolarBrane or the optimised SolarBrane, a consumer can save about $40.23 \%$ and $40.61 \%$ of the total installation cost respectively, as compared to the traditional solar PV system.

To investigate the annual output of the PV module installed, some assumptions [5]-[6] are made to ease the calculation. The solar panel is calculated based on the assumption that it will maintain $100 \%$ performance in its 25 -years lifecycle. Also, any maintenance cost is omitted from the calculation, taking into account that a good solar panel could last over a long period of time. It is also assumed that the participant opted to use $70 \%$ of the electricity generated and exports the excess $30 \%$ back into the national grid.

A $2.5 \mathrm{kWp}$ solar panel installed in Glasgow, UK could generate about $2404.44 \mathrm{kWh}$ in a year ${ }^{3}$. This translates to an annual generation income of approximately $£ 993.03$. Since $30 \%$ of the electricity is exported back into the grid, the payment received from this activity is calculated to be about $£ 18.03$ per year. The participant also uses $70 \%$ of the electricity generated, which saves him roughly $£ 225.42$ per year. Hence, the annual value of FIT from the installation totals $£ 1236.48$.

From this annual return value, the payback period for the installed solar panel is calculated for each type of solar PV. The SolarBrane using the optimised concentrator has the shortest payback period which is 6.00 years, followed by the current SolarBrane in 6.04 years. The cost of installing a traditional solar PV panel will be gained back in 10.11 years.

It is also projected that the revenue from the installation totals $£ 30,912.05$ for a period of 25 years. Therefore, the average return on investment for the traditional solar PV system, the SolarBrane using the current concentrator and

\footnotetext{
${ }^{3}$ Glasgow, UK receives an average of which has an average of 5 hours of sunlight and only $2.635 \mathrm{kWh} / \mathrm{m}^{2}$ of solar insolation per day [12],[13].
} 
the SolarBrane using the optimised concentrator is $5.89 \%, 12.55 \%$ and $12.66 \%$.

From this analysis, it can be seen that the optimised SolarBrane has three advantages; lower installation cost, shorter payback period and higher annual return on investment.

\section{Conclusion}

For any BIPV system, it is always desirable to improve the design to obtain the optimised performance. This is also true to the SolarEmpower's BIPV system, the SolarBrane. The SPOT is one of the components that form the SolarBrane. The SPOT uses a solar concentrator which focuses the solar energy into a smaller area as well as reducing the dependency on expensive PV, hence reducing the total cost of the system. The current concentrator in the SPOT is a DTIRC design based on the PCM.

An optimised design for the SolarBrane based on the MCM has been explored. This method yields almost identical structure to the design based on PCM. The geometrical analysis of the DTIRC based on MCM is presented. From the simulation results, this optimised concentrator design provides slightly higher gain, but produces a slightly larger size. The new optimised concentrator offers a lower cost of implementation, shorter payback period and an even higher annual return as compared to the existing design.

\section{Acknowledgement}

The authors would like to acknowledge the collaboration of SolarEmpower Ltd. for its contribution to this project.

\section{References}

[1]. SolarEmpower Ltd. http://www.solarempower.com/

[2]. F. Muhammad-Sukki, R. Ramirez-Iniguez, S.G. McMeekin, B.G. Stewart and B. Clive, "Optimised Dielectric Totally Internally Reflecting Concentrator for the Solar Photonic Optoelectronic Transformer System: Maximum Concentration Method", in Proc. KES 2010, Part IV, LNAI 6279, pp. 633-641.

[3]. X. Ning, R. Winston and J. O'Gallagher, "Dielectric Totally Internally Reflecting Concentrators", Applied Optics, Volume 26(2). 1987. pp. 300-305.

[4]. R. Ramirez-Iniguez, S.M. Idrus and Z. Sun, "Optical Wireless Communications: IR for Wireless Connectivity", Taylor and Francis Group LLC., (2008), pp.73-139.

[5]. Department of Energy and Climate Change, "Consultation on Renewable Electricity Financial Incentives", 2009.

[6]. Energy Saving Trust UK. http://www.energysavingtrust.org.uk/

[7]. B. Young, "Lower Carbon Heating \& Hot Water Systems -Is Zero Achievable?" in IET Seminar on Zero Carbon Buildings: Emerging Technologies and Policy Implementation, 2008, pp. 1-20.

[8]. Department of Energy and Climate Change, "Energy Consumption in the UK - Domestic Data Tables", UK, 2010. http://www.decc.gov.uk/

[9]. Solarcentury. http://www.solarcentury.co.uk/

[10]. M.J. Stern and R.T. West, "Development of a Low-Cost $15 \mathrm{~kW}$ A.C. Solar Tracking Sub-Array for Grid Connected PV Power Systems Applications", in Proc. $25^{\text {th }}$ IEEE PV Specialists Conference, 1996.

[11]. P.C. Eames, A. Zacharopoulos, D. McLarnon, T.J. Hyde and B. Norton, "Development and Experimental Characterisation of Low Cost Façade Integrated Concentrator Photovoltaics", in Proc. CIBSE2000.

[12]. BBC. http://www.bbc.co.uk/

[13]. M. Boxwell, "Solar Electricity Handbook", Code Green Publishing, (2009). pp. 113-122. 